JURNAL RUPA VOL 4 NO 1 JUNE 2019

DOI address: https://doi.org/10.25124/rupa.v4i1.2155

\title{
The Night As We Know It
}

Dike Nabila Trivinggar1, Kurniawati Gautama2*, Iqbal Prabawa Wiguna3

1,2,3Department of Visual Art, Faculty of Creative Industries, Telkom University, Bandung,

Indonesia

\begin{abstract}
Since the first invention of light bulb, humans have increasingly been accustomed to living under excessive artificial light every night. Inappropriate use of artificial light causes light pollution that now affects more than $80 \%$ world's population in densely populated cities, including Bandung City residents. The latest research shows that the rate of light pollution for high category in Bandung City has experienced an increase of 13,79 km2/year during 2013-2017. This has resulted in the loss of Bandung night sky aesthetic because the lights coming from the ground form a skyglow dome in the atmosphere, blocking most of astronomical objects light and rendering them invisible from earth. As a person who has always been interested in astronomy and is also a Bandung resident, I have concern over the long-lost Bandung night sky natural beauty due to light pollution caused by human activities. I desire to raise awareness of this issue through an installation art which explores lights, reflective paint, and video as the mediums.
\end{abstract}

Keywords: light pollution, astronomy, Bandung, installation, stargazing

$\begin{array}{ll}\text { *Kurniawati Gautama } \\ \text { Email } & : \text { gautamania@telkomuniversity.ac.id } \\ \text { Address } & : \text { Program Studi Seni Rupa, Fakultas Industri Kreatif, Universitas Telkom } \\ & \text { Jl. Telekomunikasi Terusan Buah Batu, Bandung Indonesia } 40257 \\ \text { Phone } & :+62811193869\end{array}$




\section{The Night as We Know It \\ Dike Nabila Trivinggar, Kurniawati Gautama, lqbal Prabawa Wiguna}

\section{PENDAHULUAN}

Sebagai salah satu kota pariwisata populer di Indonesia, Kota Bandung memiliki keindahan alam tak terhingga. Langit malam yang penuh bintang sesungguhnya bisa menjadi daya tarik tersendiri, sebagai kota padat penduduk yang juga menjadi kampung halaman penulis juga tak luput dari efek polusi cahaya. Hasil dari Seminar Nasional Penginderaan Jauh ke-5 oleh LAPAN di tahun 2018 melaporkan bahwa percepatan tingkat polusi cahaya di Kota Bandung sudah mencapai tingkat yang mengkhawatirkan. Dalam "Analisis Dinamika Polusi Cahaya di Sekitar Observatorium Bosscha Berdasarkan Citra Satelit VIIRS-DNB", Prastyo \& Herdiwijaya memaparkan bahwa pada tahun 2013 hingga 2017 terjadi laju peningkatan luas polusi cahaya kategori tinggi dan sedang di Kota Bandung sebesar 13,79 km2/tahun atau 9,38\%/tahun. Salah satu dampak merugikan yang diakibatkan adalah terganggunya aktivitas penelitian di Observatorium Bosscha, sebuah pusat riset astronomi di Kabupaten Bandung Barat yang juga menjadi satu-satunya observatorium besar di Indonesia. Berjarak hanya kurang lebih $20 \mathrm{~km}$ dari pusat Kota Bandung, Observatorium Bosscha kini dinilai sudah tak lagi ideal sebagai lokasi pengamatan objek-objek astronomi di malam hari, dikarenakan langit yang terlalu cerah akibat kubah-kubah cahaya yang dihasilkan dari kawasan permukiman dan perhotelan di Kota Bandung (1).

Isu polusi cahaya tak begitu banyak disadari dan dikampanyekan seperti halnya isu pencemaran udara, atau air. Banyak orang beranggapan bahwa polusi cahaya sematamata hanya persoalan para astronom, dan hilangnya langit malam berbintang bukanlah persoalan yang patut dikhawatirkan. Menurut Sébastian Giguère, Direktur Pendidikan cagar langit gelap Mont-Mégantic National Park dan koordinator saintifik pusat kegiatan astronomi ASTROLab, lenyapnya keindahan alami langit malam dan kurangnya kesadaran manusia terhadap isu tersebut sesungguhnya menjadi indikasi bagi permasalahan filosofis yang lebih mendalam. Giguère berpendapat bahwa hilangnya bintang-bintang dari angkasa dapat dihubungkan dengan relasi kita dengan alam serta cara hidup yang kita anut sebagai penghuni planet bumi. Sikap acuh kita terhadap dampak polusi cahaya berimbas pada tertutupnya satu-satunya jendela alam semesta, dimana hal ini menjadi simbol bagaimana manusia memisahkan diri dari alam. Menurut Giguère, hanya dengan mampu memandangi titik-titik mungil di angkasa, akan timbul kesadaran betapa indah dan luasnya luar angkasa, yang pada akhirnya membangun rasa memiliki dan bertanggung jawab dalam diri manusia terhadap langit dan alam secara keseluruhan. (2)

Indahnya langit malam juga memantik imajinasi dan membangkitkan inspirasi bagi banyak seniman hebat seperti Vincent van Gogh, komponis Holst, dan penulis Shakespeare dalam menciptakan karya-karya agung yang masih dikagumi hingga kini. Edvard Munch, Frederic Edwin Church, dan Georgia O'Keeffe juga termasuk tokoh-tokoh perupa yang pernah menciptakan karya besar yang terinspirasi dari keindahan alami langit malam. Langit gelap yang bersih dari cahaya polutan merupakan hak bagi setiap manusia yang sangat bernilai bagi kemajuan peradaban. Delapan puluh persen manusia di bumi sudah terlalu lama tidak melihat bintang di langit sehingga mereka tidak menyadari apa yang telah direnggut dari malam-malam yang terlewat begitu saja. Jika polusi cahaya terus berlanjut dengan percepatan yang konstan, maka bukan tidak mungkin bahwa anak cucu kita akan menyanyikan lagu "Bintang Kecil" tanpa pernah tahu wujud bintang kecil yang sesungguhnya, kecuali lewat penggambaran dalam buku atau televisi yang tak akan 
pernah membangkitkan imajinasi dalam benak mereka yang penuh rasa ingin tahu seperti halnya memandangi langsung kearah langit malam.

Permasalahan yang telah dikemukakan di atas kemudian menjadi latar belakang bagi penciptaan karya, yang dimaksudkan untuk membangkitkan kesadaran terhadap isu polusi cahaya, di kota Bandung pada khususnya, dan mengingatkan kembali pirsawan terhadap keindahan langit malam yang telah direnggut oleh cahaya artifisial.

\section{KONSEP KARYA}

Dari daratan bumi, mata telanjang manusia dengan tingkat penglihatan normal dapat melihat sekurang-kurangnya 2000 hingga 3000 bintang yang berasal dari Galaksi Bima Sakti, dan sebagian kecil berasal dari Galaksi Andromeda. Beberapa orang dengan penglihatan diatas rata-rata bahkan dapat melihat hingga 7000 bintang. (3) Selain kemampuan visual alami, manusia dianugerahi rangkaian otot-otot yang memungkinkan kita mendongakkan kepala ke atas dalam waktu cukup lama tanpa kehilangan keseimbangan. Keunggulan inilah, menurut Bob Mizon (2012), yang menjadi salah satu kunci yang membuka pintu menuju perasaan takjub dan keingintahuan mendalam atas apa yang ada di langit serta kontemplasi atas skema alam semesta yang lebih agung dari segala hal di sekitar kita.

Tanpa adanya polusi cahaya, menatap ribuan bintang di langit dapat menjadi sebuah pengalaman estetis sehari-hari bagi siapa saja, termasuk orang yang tinggal di perkotaan. Sayangnya, lambat laun kemungkinan tersebut semakin sulit untuk diwujudkan lantaran manusia semakin terbiasa hidup dalam kondisi malam yang terang benderang oleh cahaya artifisial berlebihan yang mengalahkan cahaya milyaran bintang di langit. Kondisi ini dapat dijelaskan dengan teori John Dewey, yang mengungkap bahwa kualitas estetika sesungguhnya hadir secara implisit di dalam setiap pengalaman normal sehari-hari, namun pengalaman tersebut seringkali gagal untuk muncul secara eksplisit. (4) Kegagalan tersebut terjadi karena organisme tidak berhasil melakukan interaksi yang cukup baik dengan lingkungan di sekitarnya, salah satunya dikarenakan kebiasaan dan kondisi familiar di sekitar manusia-dalam kasus ini adalah lingkungan dengan cahaya artifisial berlebihan-yang berlarut-larut menimbulkan keacuhan dan menutup kemungkinan terhadap terjadinya pengalaman estetis. (5)

Karya yang dihasilkan penulis bertujuan menampilkan representasi dualisme situasi malam hari luar ruangan di dalam sebuah ruang pamer. Karya yang diberi judul "The Night as We Know It" diwujudkan dalam bentuk instalasi meruang, dimana menurut penulis merupakan bentuk yang paling tepat lantaran seni instalasi mampu menghadirkan situasi yang bersifat experiential dan teatrikal.

Karya instalasi tersusun antara lain atas:

1) Ruangan hitam

Ruangan dibuat serba hitam untuk menjadi representasi dari situasi malam hari yang gelap.

2) Empat buah lampu floodlight pada masing-masing sudut langit-langit ruangan

Lampu floodlight yang terpasang pada empat sudut atas ruangan menjadi representasi dari penggunaan lampu berlebihan dan tidak tepat guna. Lampu ini diprogram untuk bisa mati dan menyala dalam hitungan detik dan menyorot ke arah bawah/ lantai ruangan. Nyala dan matinya lampu dikendalikan oleh sebuah saklar yang terpasang dalam ruangan.

3) Mural diatas lantai

Terdapat karya mural yang dibuat di atas lantai, dengan visual berupa denah jalan utama di Kota Bandung. Mural ini merepresentasikan bumi yang sedang dipijak audiens, yakni Kota Bandung. Keberadaan mural dimaksudkan untuk lebih menekankan tentang identitas tempat dalam isu yang sedang dibicarakan dalam karya. Mural dibuat reflektif atau memantulkan cahaya sehingga hanya terlihat saat 
ada cahaya lampu, yang merepresentasikan: 1) garis-garis jalanan kota yang bercahaya jika dilihat dari satelit dan 2) sifat jalanan aspal yang bersifat memantulkan cahaya

4) Proyeksi langit malam

Sebuah proyektor dipasang di salah satu sisi ruangan, dan diarahkan ke atas atau ke langit-langit ruangan. Penulis akan membiarkan proyektor tersebut menyala sepanjang waktu. Video yang diproyeksikan adalah imaji langit malam Bandung secara realtime, atau langit yang dapat tampak pada malam di hari yang sama saat audiens berada di dalam karya.

5) Saklar sensor sentuh

Elemen partisipatoris dalam karya ditekankan pada keberadaan saklar sensor sentuh di salah satu sisi ruangan. Audiens bebas untuk menyentuh saklar tersebut, dimana ketika disentuh, lampu di dalam instalasi akan menyala/mati dan mengubah situasi dalam karya. Sensor sentuh digunakan untuk merepresentasikan bagaimana sedikit sentuhan dari manusia sebagai metafora dari 'campur tangan' dapat mengikis keindahan alam. Gestur menyalakan dan mematikan lampu juga menjadi simbolisasi bagaimana polusi cahaya, tak seperti polusi udara, air, dan tanah, merupakan jenis polusi yang bersifat reversible. Hal ini berarti bahwa lingkungan yang terdampak masih dapat 'dibersihkan' dari polutan cahaya dengan cara meminimalisir sumbernya, salah satunya dengan mematikan lampu yang tidak terpakai atau tidak dibutuhkan.

\section{Pengadeganan}

Pada saat audiens memasuki ruangan, keempat lampu berada dalam kondisi menyala dan menerangi seluruh sudut instalasi. Sebagai efeknya, mural peta Bandung pada lantai terlihat oleh audiens. Ketika saklar disentuh, keempat lampu akan satu persatu mati dalam hitungan 3 detik per lampu. Setelah semua lampu mati dan ruangan perlahan menjadi gelap gulita, terjadi perpindahan imaji dari bawah ke atas, dimana karya mural di atas lantai tak lagi terlihat dan sebagai gantinya visual langit malam bertabur bintang dengan keindahan gugusan galaksi Bima Sakti dari proyektor terlihat di langit-langit ruangan. Situasi kedua ini menjadi penggambaran malam hari tanpa polusi cahaya dimana manusia dapat menikmati pengalaman estetis memandangi langit malam dengan keindahan alaminya yang kontemplatif. Ketika saklar disentuh kembali, keempat lampu akan menyala satu persatu dengan jeda satu detik per lampu dan cahayanya akan mengalahkan sinar proyeksi video dari proyektor sehingga tidak lagi terlihat di langitlangit. Pada saat ini terjadi perpindahan kembali imaji dari atas ke bawah, dimana bintangbintang tak lagi terlihat dan peta Bandung di bawah terlihat oleh audiens. Adegan ini menggambarkan bagaimana cahaya lampu berlebihan di kota menghapus cahaya-cahaya bintang di langit, sebuah situasi malam hari yang dihadapi warga Kota Bandung seharihari tanpa disadari. Irama nyala dan matinya lampu ditambahkan penulis, selain untuk menambahkan efek dramatis, juga untuk memberi pembeda waktu pada saat lampu mati dan menyala ketika saklar disentuh. Jeda waktu masing-masing lampu ketika mati lebih lama daripada ketika menyala, menjadi metafora bagaimana usaha manusia untuk menekan laju polusi cahaya jauh lebih lambat daripada mempercepat tingkat polusi cahaya itu sendiri.

\section{PROSES BERKARYA}

1. Menentukan lokasi display karya:

Lokasi terpilih merupakan ruangan berukuran $4.3 \mathrm{~m} \times 3.3 \mathrm{~m} \times 2.6 \mathrm{~m}$ di Studio Batur, yang berlokasi di Jalan Bukit Pakar Utara, Bandung.

2. Pembuatan sketsa mural:

Dalam merancang konsep visual mural, penulis mengacu pada peta jalan (street map) Bandung yang ditampilkan oleh situs Google Map. Penulis membuat sketsa dengan nuansa monokrom dalam bentuk digital menggunakan piranti lunak.

3. Pembuatan sketsa layout instalasi 
Untuk semakin mempermudah penciptaan karya, penulis membuat sketsa layout ruangan beserta instalasi secara tiga dimensi dengan menggunakan perangkat lunak SketchUp.

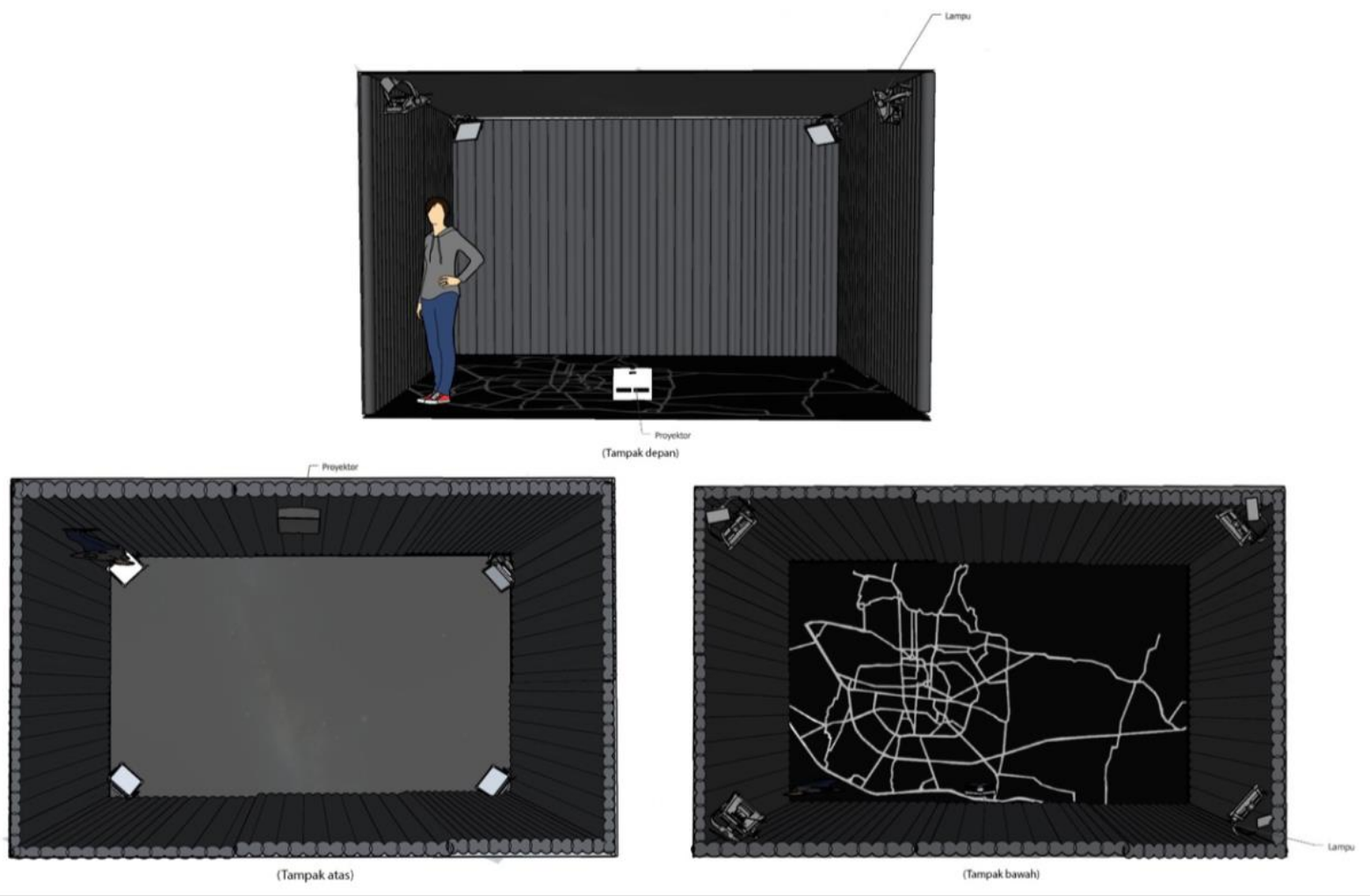

Gambar 2 Sketsa layout instalasi saat lampu menyala
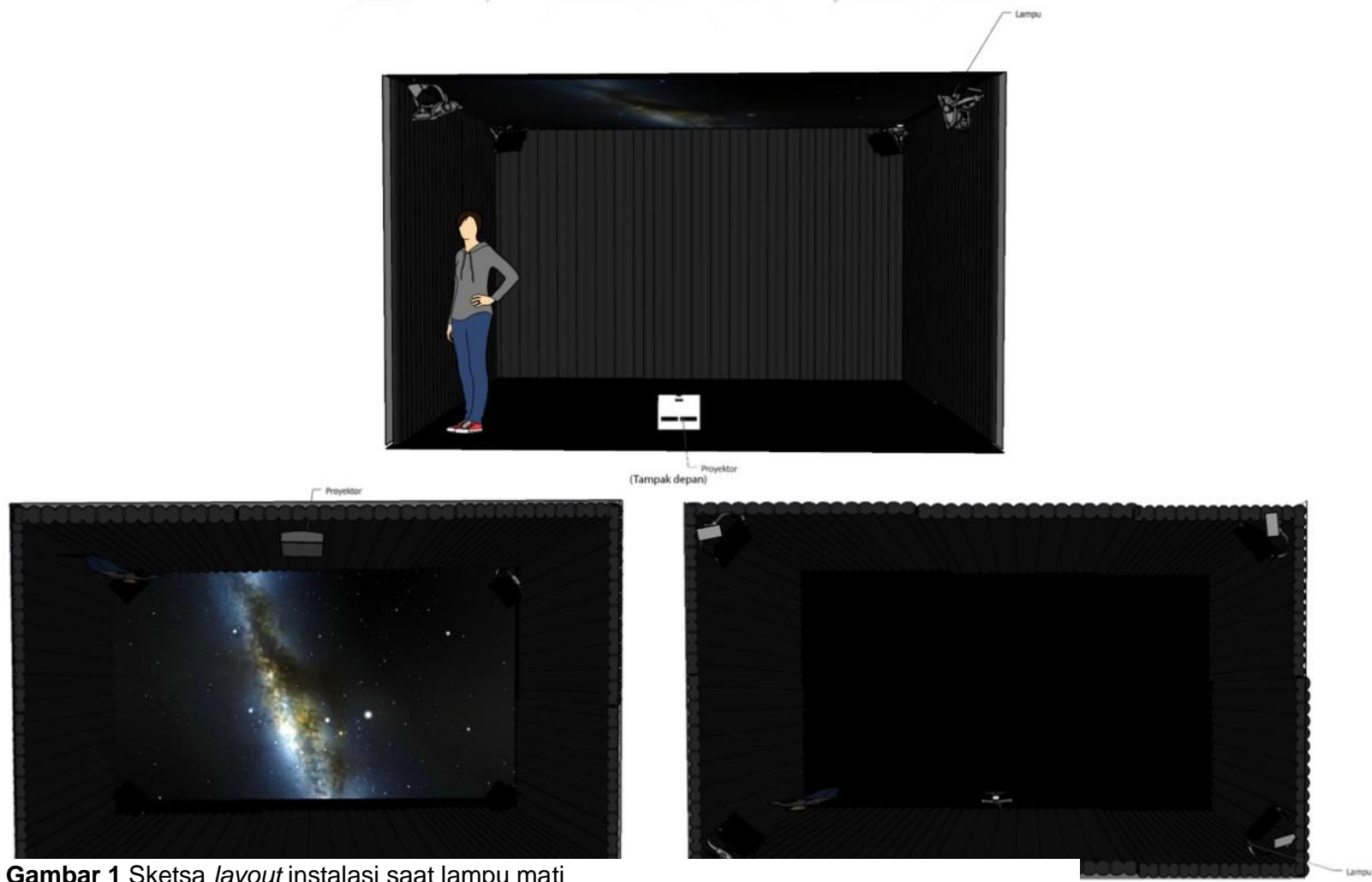

Gambar 1 Sketsa layout instalasi saat lampu mati 
4. Pemilihan dan persiapan medium:

1) Proyektor:

Proyeksi video dimaksudkan untuk memenuhi setidaknya $3 / 4$ langit-langit yang berukuran $4 \times 3$ meter. Dengan memperhitungkan tinggi langit-langit yang kurang dari 3 meter, maka penulis memerlukan proyektor yang mampu menembakkan proyeksi gambar berukuran besar dari jarak yang cukup dekat. Perangkat yang dipilih adalah proyektor tipe short throw dengan merk "Infocus".

2) Perangkat lunak planetarium "Stellarium"

Guna menyajikan visualisasi langit malam yang realistis, akurat, dan berbasis waktu yang sebenarnya (realtime), penulis menggunakan "Stellarium", sebuah perangkat lunak simulasi langit.

3) Cat mural

Demi memberikan kesan berpendar pada mural peta, penulis menggunakan cat semprot reflektif (bersifat memantulkan cahaya) dengan merk 'Are Glow Up'.

4) Lampu dan perangkat konfigurasi lampu

Penulis memilih lampu LED tipe floodlight tanpa tudung dengan warna cahaya putih sebagai medium untuk menyuguhkan cahaya dalam ruang. Floodlight merupakan tipe lampu dengan intensitas tinggi yang sering kita jumpai di jalan-jalan atau penggunaan luar ruang seperti area parkir, arena olahraga, dan penerangan papan reklame. Dalam diagram panduan lampu yang disarankan oleh situs darksky.org, lampu floodlight masuk dalam kategori yang tidak disarankan. Secara total, penulis menggunakan empat buah lampu LED floodlight yang masing-masing ditempatkan di sudut langit-langit ruangan.

Untuk mewujudkan skema nyala dan mati lampu secara satu persatu dalam jeda hitungan detik, penulis membuat pemrograman lampu menggunakan perangkat lunak Arduino. Perangkat keras yang digunakan antara lain Arduino Uno, Relay Module 4 channel, dan saklar sensor sentuh.

5) Kain Hitam

Penulis memilih untuk menggunakan kain hitam berukuran $28 \times 3$ meter untuk menutupi seluruh dinding ruang pamer yang berwarna putih. Selain memberikan kesan gelap, penggunaan kain hitam juga dimaksudkan untuk menghalangi cahaya dari luar ruangan masuk ke dalam karya instalasi dan juga untuk menambah kesan teatrikal.

5. Pembuatan maket karya

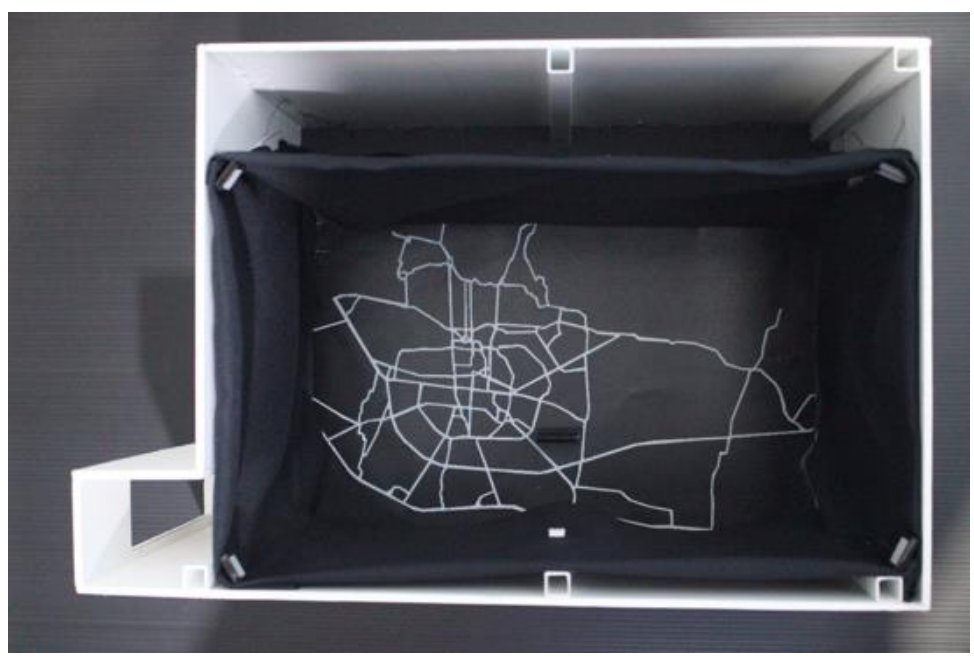

Gambar 3 Maket karya skala 1:15 
6. Pemasangan karya di ruang pamer

Tahap proses pemasangan karya di ruang pamer secara berurutan meliputi pemasangan empat lampu floodlight, pembuatan mural diatas lantai, pemasangan perangkat Arduino dan saklar di dalam ruangan, dan tahap terakhir adalah pemasangan tirai hitam di seluruh sisi dinding ruangan.

7. Hasil akhir karya Instalasi:
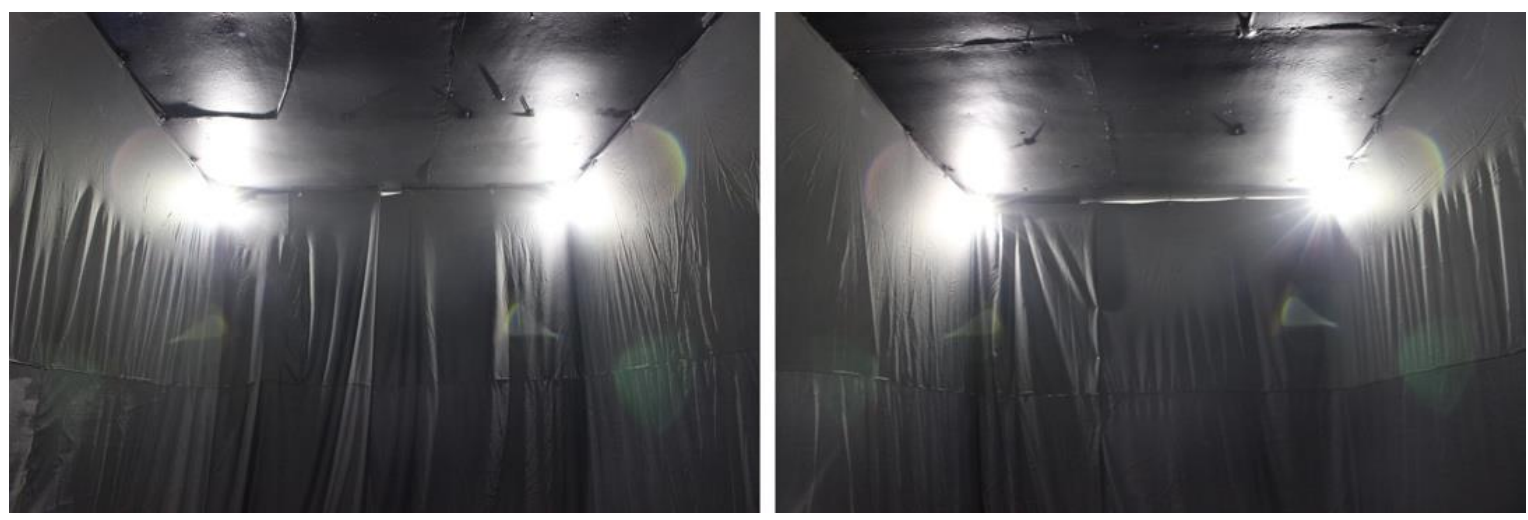

Gambar 4 Tampak samping instalasi
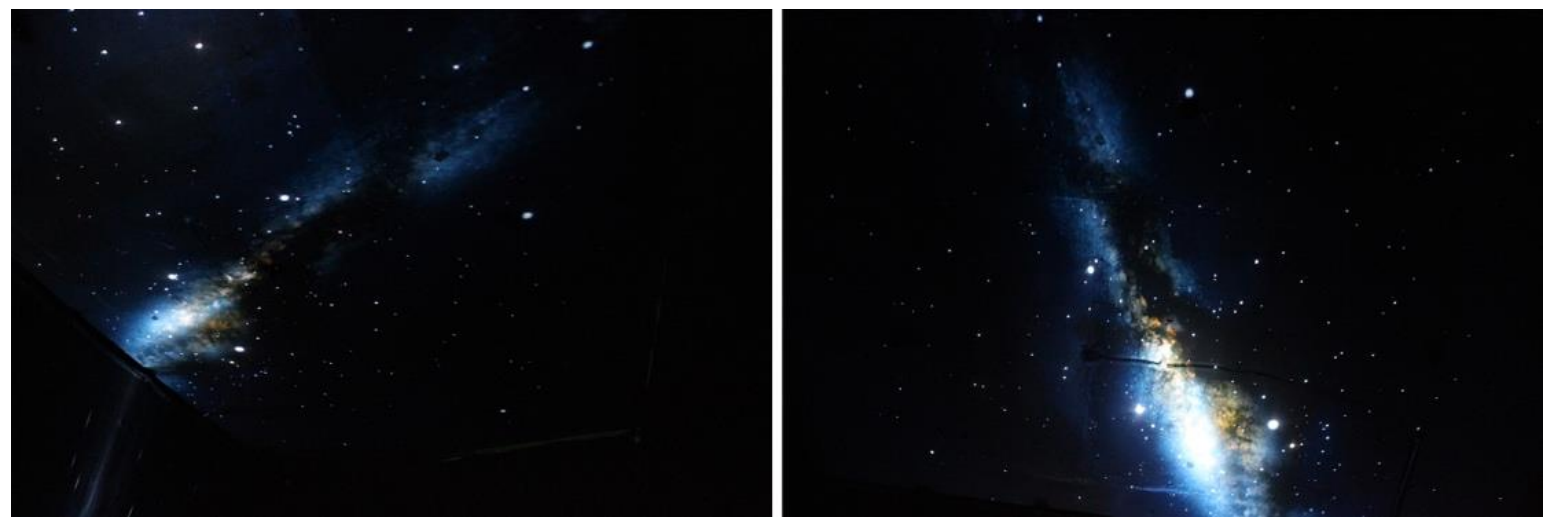

Gambar 5 Tampak atas instalasi
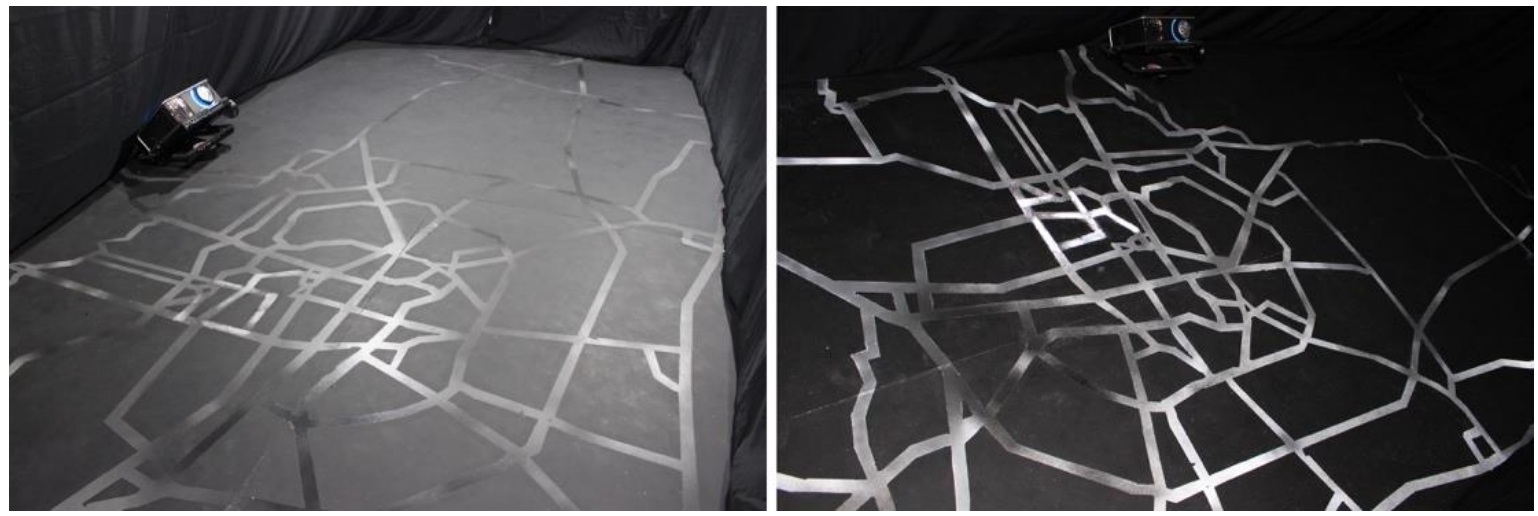

Gambar 6 Tampak bawah instalasi 


\section{KESIMPULAN}

Karya penulis diwujudkan melalui medium seni instalasi meruang yang bersifat interaktif yang memadukan media campuran antara lain lampu floodlight, cat reflektif, proyeksi video dan kain hitam untuk menyajikan pengalaman estetis dan membangkitkan kesadaran atas dampak polusi cahaya terhadap estetika langit gelap. Seni instalasi dipilih karena medium ini mampu menghadirkan situasi yang teatrikal, experential, dan imersif. Lampu floodlight dan cat reflektif digunakan untuk merepresentasikan kondisi malam hari dengan polusi cahaya, dimana floodlight secara langsung mewakili lampu luar ruang yang menimbulkan pencemaran tinggi. Sementara medium cat reflektif dipilih karena sifatnya yang dapat merespon nyala lampu dengan cara memantulkan cahaya. Penulis menggunakan proyektor untuk menampilkan video langit malam hari yang realistis dan realtime dalam kondisi tanpa polusi cahaya, dengan bantuan perangkat lunak planetarium 'Stellarium'. Elemen interaktif dari karya instalasi diperkuat dengan kehadiran saklar lampu dimana pengunjung dapat menggunakannya untuk menyalakan dan mematikan lampu guna mengubah situasi di dalam ruangan.

\section{UCAPAN TERIMAKASIH}

Kami mengucapkan puji dan syukur kepada Allah SWT atas segala rahmat dan hidayahNya sehingga karya dan tulisan ini dapat terselesaikan dengan baik. Terima kasih juga kami haturkan kepada Studio Batur, terutama Fajar Abadi RDP, S.Sn selaku pemilik studio dan Yunisti Ambarsari, S.Ds selaku pengelola atas segala waktu dan kesediaannya dalam memberikan bantuan tak terhingga dalam penyelesaian karya ini. Kami berterimakasih pada Ahmad Bismillahi Normansyah, S.Si dan para staf Observatorium Bosscha yang menjadi rekan diskusi kami dalam keilmuan astronomi. Kami berterimakasih pada Ibu Dea Aulia Widyaevan, S.T, M.Sn, dan Bapak Aulia Ibrahim Yeru, S.Ds, M.Sn atas segala kritik dan saran membangun yang telah diberikan untuk karya dan penulisan artikel ini. Terimakasih juga kami sampaikan kepada Universitas Telkom, dan program studi Seni Rupa pada khususnya.

\section{DAFTAR PUSTAKA}

(1) Prastyo, Hendra Agus, and Dhani Herdiwijaya. 2018. Analisis Dinamika Polusi Cahaya di Sekitar Observatorium Bosscha Berdasarkan Citra Satelit VIIRS-DNB. Seminar Nasional Penginderaan Jauh ke-5 Tahun 2018. ResearchGate. Bandung.

(2) Bogard, Paul. 2013. The End of Night. p.199. Fourth Estate. London.

(3) Mizon, Bob. 2012. Light Pollution: Responses and Remedies. 2nd Edition. p.11. Springer. New York.

(4) Dewey, John. 2005. Art as Experience. p.18. Tarcher Perigee. New York.

(5) Stroud, Scott R. 2014. The Art of Experience: Dewey on the Aesthetic. Practicing Pragmatist Aesthetics: Critical Perspectives on the Arts. p.34. Edited by Wojciech Malecki. Rodopi. Amsterdam. 